\title{
Enhancing the Shelf-Life of Fresh Cassava Roots: A Field Evaluation of Simple Storage Bags
}

\author{
Keith Tomlins ${ }^{1}$, Aditya Parmar ${ }^{1, *(1)}$, Celestina Ibitayo Omohimi ${ }^{2}$, Lateef Oladimeji Sanni ${ }^{2}$, \\ Adekola Felix Adegoke ${ }^{2}$, Abdul-Rasaq Adesola Adebowale ${ }^{2}$ and Ben Bennett ${ }^{1}$ (D) \\ 1 Food and Markets Department, Natural Resources Institute, University of Greenwich, Central Avenue, \\ Chatham Maritime, Kent ME4 4TB, UK; k.i.tomlins@greenwich.ac.uk (K.T.); \\ ben.bennett@greenwich.ac.uk (B.B.) \\ 2 Department of Food Science and Technology, Federal University of Agriculture, PMB 2240, \\ Abeokuta 110001, Nigeria; get2tina2@yahoo.com (C.I.O.); sannilateef5@gmail.com (L.O.S.); \\ saintadekolaadegoke@yahoo.com (A.F.A.); rasaq.debo@gmail.com (A.-R.A.A.) \\ * Correspondence: a.parmar@greenwich.ac.uk; Tel.: +44-0-1634-883070
}

\section{check for} updates

Citation: Tomlins, K.; Parmar, A.; Omohimi, C.I.; Sanni, L.O.;

Adegoke, A.F.; Adebowale, A.-R.A.; Bennett, B. Enhancing the Shelf-Life of Fresh Cassava Roots: A Field Evaluation of Simple Storage Bags. Processes 2021, 9, 577.

https://doi.org/

doi:10.3390/pr9040577

Academic Editors: Daniel I. Onwude and Guangnan Chen

Received: 9 March 2021

Accepted: 23 March 2021

Published: 26 March 2021

Publisher's Note: MDPI stays neutral with regard to jurisdictional claims in published maps and institutional affiliations.

Copyright: (c) 2021 by the authors. Licensee MDPI, Basel, Switzerland. This article is an open access article distributed under the terms and conditions of the Creative Commons Attribution (CC BY) license (https:/ / creativecommons.org/licenses/by/ $4.0 /)$.

\begin{abstract}
Postharvest physiological deterioration (PPD) of fresh cassava roots limits their shelf-life to about $48 \mathrm{~h}$. There is a demand for simple, cheap, and logistically feasible solutions for extending the shelf life of fresh cassava roots in industrial processes. In this study, three different types of bag materials were tested, namely woven polypropylene, tarpaulin, and jute as a potential storage solution for cassava roots with different levels of mechanical damage. Microclimate related to temperature, humidity, and carbon di-oxide $\left(\mathrm{CO}_{2}\right)$ was monitored in order to understand the storage conditions for up to 12 days. The results showed that fresh cassava roots could be stored for 8 days, with minimal PPD and starch loss (2.4\%). However, roots with significant mechanical damage in the form of cuts and breakages had a considerably shorter shelf life in the storage bag, compared to whole roots and roots with retained stalk (peduncle) where roots are connected to the main plant. Wetting of the roots and bag material were not significant factors in determining the shelf life and starch loss. Carbon dioxide concentration in the stores was significantly correlated with the starch loss in fresh cassava roots and is proposed as a possible method for continuously and remotely monitoring starch loss in large-scale commercial operations and reducing postharvest losses.
\end{abstract}

Keywords: cassava; storage; PPD; starch; shelf-life; postharvest losses

\section{Introduction}

The short shelf-life of cassava (Manihot esculenta C.) roots is primarily attributed to postharvest physiological deterioration (PPD), which is triggered as a wound response shortly after harvest [1-3]. PPD reduces the quality and quantity of starch and renders the cassava roots unmarketable and inedible. PPD is a complex process, and its exact mechanism is still not fully understood [2,4,5]; however, it is known that it involves enzymatic stress responses to wounds and changes in gene expression. PPD can be accompanied by moisture and starch loss $[4,6,7]$. It results in the formation of blue-black internal root discolouration (vascular streaking) because of the combination of insoluble precipitates formed from scopoletin reacting with hydrogen peroxide. Cassava roots can also suffer from fungal rots. Cassava varieties have been reported to differ in storability $[2,8]$ concerning PPD.

Various attempts have been made in the past to store fresh cassava in various conditions to control PPD and enhance the overall shelf life of fresh cassava roots. Several factors appear to be important for storing roots under ambient tropical conditions; these include curing, cassava variety, chemical treatments, the container, or bag that the roots are stored in, and physical damage to the roots due to harvesting and handling. Curing of the fresh cassava roots is a critical factor; it is the process of wound healing and has been 
shown to reduce storage losses of slightly damaged roots [4,7]. The optimum conditions for curing are a humidity of $80-85 \%$ and a temperature of 25 to $35^{\circ} \mathrm{C}$ [9-11]. Previous studies on the storage of fresh cassava roots have reported durations of 11 days [12-14], 11 to 21 days [15], 14 days [16], one month, and two months under cooler conditions. However, these experiments were undertaken in laboratory conditions with small quantities and lacked practical applications in a commercial setting where tons of roots arrive every day at the processing plant. The limited research at a larger scale, such as the storage of $300 \mathrm{~kg}$ of roots in Colombia [12,13] and $500 \mathrm{~kg}$ in Tanzania, indicates that the roots can store well in larger quantities, but there was no replication and hence the information is limited.

Since cassava is a low-value crop, the challenge is to find a reliable solution at a low cost. The hypothesis for this study was that PPD in fresh cassava can be restricted at scale by the application of a low-cost simple bag storage method along with control measures that might include bag design and the control of moisture, root damage, and variety. To test this, we addressed the following questions for storage at scale:

1. Does the type of storage bag material used to store fresh cassava roots influence storability?

2. Is wetting the roots important?

3. What is the maximum level of fresh root damage (including the peduncle) while still offering acceptable fresh root quality after storage?

4. Does the cassava root variety affect PPD (in industry roots are often mixed, so sorting would be difficult)?

5. What is the impact on starch loss (a critical parameter for commercial-scale operation), and can methods to continuously monitor starch loss during the storage of fresh cassava roots be suggested?

\section{Materials and Methods}

The research was undertaken during the main harvest period in Nigeria in 2018 and 2019. All experiments were conducted at the Federal University of Agriculture, Abeokuta, Ogun State, Nigeria in an experimental barn for root and tuber crops and at ambient temperature $\left(23-32^{\circ} \mathrm{C}\right)$ and humidity $(56-100 \%)$. Due to the need to harvest, sort, weigh, transport, and handle large quantities of fresh cassava roots, a stepwise approach to minimize logistical challenges was adopted (Figure 1).

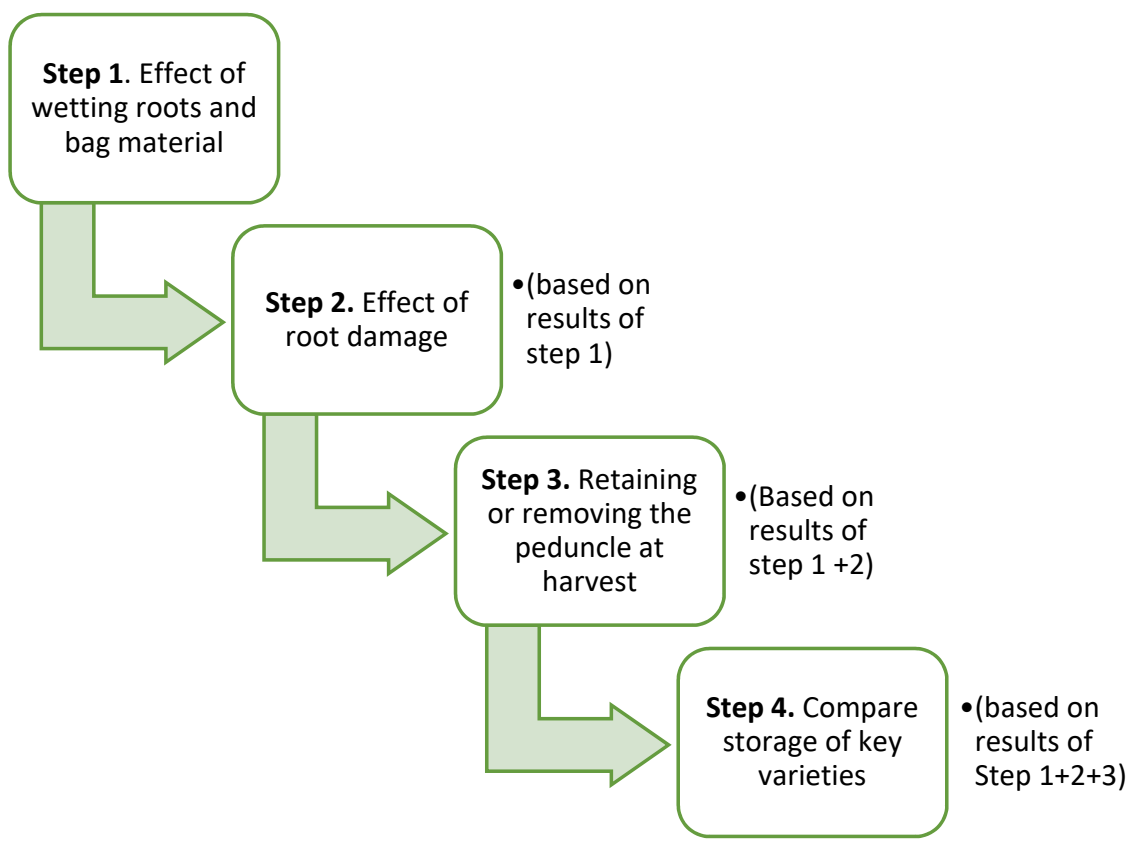

Figure 1. Stepwise progression in experiments to investigate shelf-life at scale. 


\subsection{Cassava Roots}

Fresh roots of variety TME (Tropical Manihot Esculenta) 419 were used in the experiments unless stated otherwise. They were manually harvested and sorted. In the field, exposure of the roots to direct sunlight was avoided and roots were transported from the field to the research station within $2-3 \mathrm{~h}$ of harvest. The variety TME 419 was selected to develop the storage method because it is mostly preferred by farmers and commercial industries in Nigeria. It has high yields, higher starch content, and matures early in the growing season [3]. Two additional varieties, namely, TMS (Tropical Manihot Species) 0581 and TMS 1632, were used for the varietal comparison.

\subsection{Bag Material and the Effect of Wetting}

Three types of bag material were compared: woven polypropylene (1390 $\mathrm{mm}$ long by $789 \mathrm{~mm}$ wide by $0.7 \mathrm{~mm}$ thick), tarpaulin (1180 $\mathrm{mm}$ long by $853 \mathrm{~mm}$ wide by $0.6 \mathrm{~mm}$ thick), and jute (1083 mm long by $823 \mathrm{~mm}$ wide by $2.1 \mathrm{~mm}$ thick). These were selected based on previous research [13] and availability in Nigeria. Bags were locally purchased. Additionally, fresh roots were either wetted with water (to provide high humidity) or not wetted. Controls were roots heaped on the ground without using any bag materials. Table 1 illustrates the experimental design for bag material and the effect of wetting.

Table 1. Experiment design for bag material and wetting of roots.

\begin{tabular}{|c|c|c|c|}
\hline Bag Material & $\begin{array}{c}\text { Wetted (W)/ } \\
\text { Non-Wetted (NW) }\end{array}$ & Replicates & Weight of Root for Each Replicate (kg) \\
\hline \multirow{2}{*}{ Woven polypropylene (WP) } & Wetted & 5 & 50 \\
\hline & Not wetted & 5 & 50 \\
\hline \multirow{2}{*}{ Tarpaulin $(\mathrm{T})$} & Wetted & 5 & 50 \\
\hline & Not wetted & 5 & 50 \\
\hline \multirow{2}{*}{ Jute (J) } & Wetted & 5 & 50 \\
\hline & Not wetted & 5 & 50 \\
\hline \multirow{2}{*}{ Control (no bag) (C) } & Wetted & 5 & 50 \\
\hline & Not wetted & 5 & 50 \\
\hline
\end{tabular}

Fresh cassava root samples were either wetted (dipping in clean water) or not wetted. Roots $(50 \mathrm{~kg}$ ) were placed in three bag types, constructed of either polypropylene, jute, or tarpaulin, and control roots (wetted and unwetted) were heaped on the floor. All treatments were replicated five times. Roots from each treatment $(5 \mathrm{~kg})$ were randomly sampled at $48 \mathrm{~h}$ intervals for weight loss, PPD, fungal rot, and starch content measurements for a duration of up to 12 days.

The carbon dioxide $\left(\mathrm{CO}_{2}\right)$, temperature $\left({ }^{\circ} \mathrm{C}\right)$, and relative humidity $(\mathrm{RH} \%)$ levels were measured using a Rotronics CP11 datalogger (Rotronics Instruments (UK) Ltd., Crawley, West Sussex, UK). They were set to record continuously during the experiments. The data loggers were fitted inside a ventilated plastic tube $(68 \mathrm{~mm} \times 300 \mathrm{~mm})$ which was situated in the centre of each sack or a pile of roots.

\subsection{Effect of Mechanical Root Damage}

Woven polypropylene sacks were filled with $50 \mathrm{~kg}$ wetted fresh cassava roots (TME 419) with the following treatments being either one break, two breaks, no breaks but slight bruising, no breaks with extensive bruising, and roots with no breaks and no bruising. The breaks were obtained by cutting roots with a knife. All treatments were replicated five times. Cassava roots $(5 \mathrm{~kg}$ ) were sampled for a period of 12 days, every two days. Table 2 illustrates the categories of mechanical damage. 
Table 2. Categories of mechanical damage to cassava roots.

\begin{tabular}{|c|c|c|}
\hline Damage Class & Definition & Pictorial Representation * \\
\hline One break & $\begin{array}{l}\text { One break only and a significant proportion of } \\
\text { the root remaining }\end{array}$ & \\
\hline Two breaks & $\begin{array}{l}\text { Two breaks in the root but with a significant } \\
\text { proportion of the root remaining }\end{array}$ & \\
\hline No breaks & The root is intact and has no visible bruising & \\
\hline Slight bruising & $\begin{array}{l}\text { The surface of the root is only slightly bruised } \\
\text { and estimated to be } 10 \% \text { or less of the surface } \\
\text { area }\end{array}$ & \\
\hline Severe bruising & $\begin{array}{l}\text { The root is severely bruised and affects most of } \\
\text { the visible surface }\end{array}$ & \\
\hline
\end{tabular}

* Where yellow area represents bruising of the surface of the root.

\subsection{Harvesting with and without the Peduncle}

Woven polypropylene sacks were filled with $50 \mathrm{~kg}$ wetted fresh cassava roots (TME 419) with the following treatments being either root with the peduncle still attached or root without (Table 3). Control roots were not stored in sacks. All treatments were replicated five times. Cassava roots $(5 \mathrm{~kg})$ were sampled at zero, two, four, six and eight, ten, and twelve days.

Table 3. Cassava roots harvested with and without the peduncle.

Damage Class
Without peduncle

\subsection{Varietal Comparison}

Woven polypropylene sacks were filled with $50 \mathrm{~kg}$ wetted fresh cassava roots (TMS 0581, TMS 1632, and TME 419) with the following treatments being either root with the peduncle still attached or root without peduncle. Control sample cassava roots were not stored in sacks. All treatments were replicated five times. Cassava roots $(5 \mathrm{~kg})$ were sampled at zero, two, four, six, eight, ten, and twelve days.

\subsection{Weight Loss, PPD, and Fungal Rot Measurement}

The weight of the fresh cassava roots was recorded every $24 \mathrm{~h}$ for a period of 12 days to measure the weight loss during storage in different bag materials and without any bags (control). The PPD for each treatment was measured based on seven transversal slices 
of $2 \mathrm{~cm}$ thickness which were cut along the root, starting from the proximal end [7]. A score of $0-1$ was assigned to each slice by an expert panel of three people (cassava crop physiologists and postharvest scientists), corresponding to the percentage of the transversal cut surface showing vascular discolouration (which represents PPD) $(0.1=10 \%, 0.2=20 \%$, etc.). The mean score of PPD for each root was calculated as the final measurement. For fungal rotting incidence, roots were visually scored from 0 to 5 (by the same expert panel), where 0 means no rotting and 5 severe rotting.

\subsection{Starch Content Measurement}

Starch was measured using the same method as used by the industry in Nigeria, that is, the Reimann Balance (Specific Gravity) Method (1986) (Figure 2). This is recommended by the International Starch Institute, Science Park, Aarhus, Denmark. The calculated data is in per cent, and deviates less than 0.05 from the values readout of the EU table enforced by the European Commission covering potatoes with $13 \%$ to $23 \%$ starch dry matter. A calibrated Kern CH 15K20 weighing balance was used (RS Components Ltd., Northants, UK).

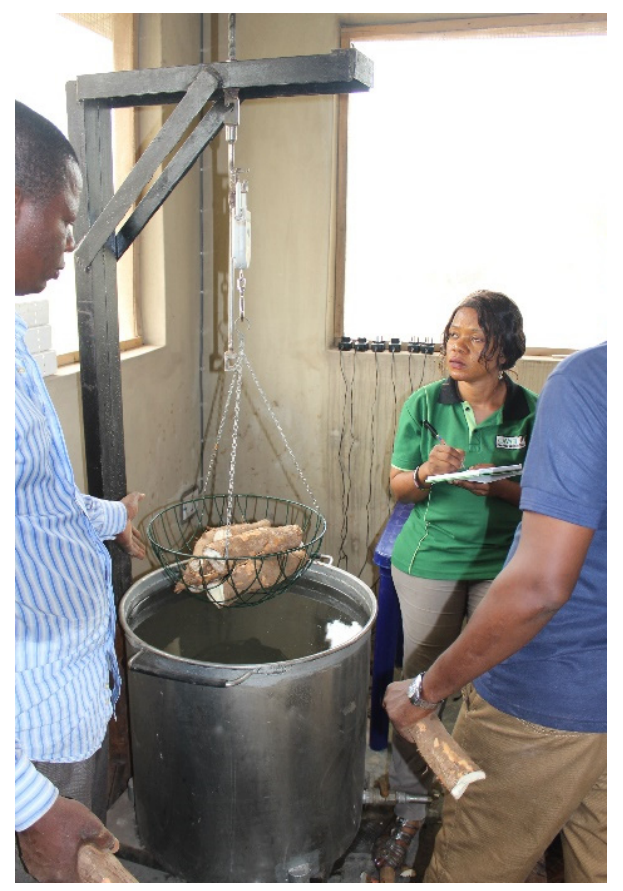

Figure 2. Reimann Balance (Specific Gravity) Method as constructed at the Federal University of Agriculture, Abeokuta, Nigeria.

\subsection{Statistical Analysis}

Data were analysed by analysis of covariance (ANCOVA) procedures using R, (Version 3.6.3, R Core team, Vienna, Austria, 2020) and IBM SPSS Statistics, Version 25.0. (Armonk, NY, USA: IBM Corp) statistical packages with the least significant difference (LSD) at $p=0.05$ and linear regression.

\section{Results}

\subsection{Comparison of the Storage Bag Materials and Wetting}

Loading bags with either dry cassava roots or roots that had been wetted with water did not result in any significant differences in root quality concerning PPD, fungal rot, starch content, or root moisture content $(p<0.05)$. Therefore, wet and non-wet scores were combined for the subsequent analyses. This lack of a significant effect of wetting is probably because the humidity within the sacks of cassava roots remained above $85 \%$ $\mathrm{RH}$ [1] regardless of whether the roots were wetted or not, as illustrated in Figure 3. It 
is speculated that wetting the roots is probably important to maintain relative humidity above $85 \%$ in a small-scale laboratory context due to the small number of roots involved; where larger qualities of roots are involved (in this case $50 \mathrm{~kg}$ ), the natural respiration is probably sufficient to keep the relative humidity above $85 \%$, as demonstrated in this study.

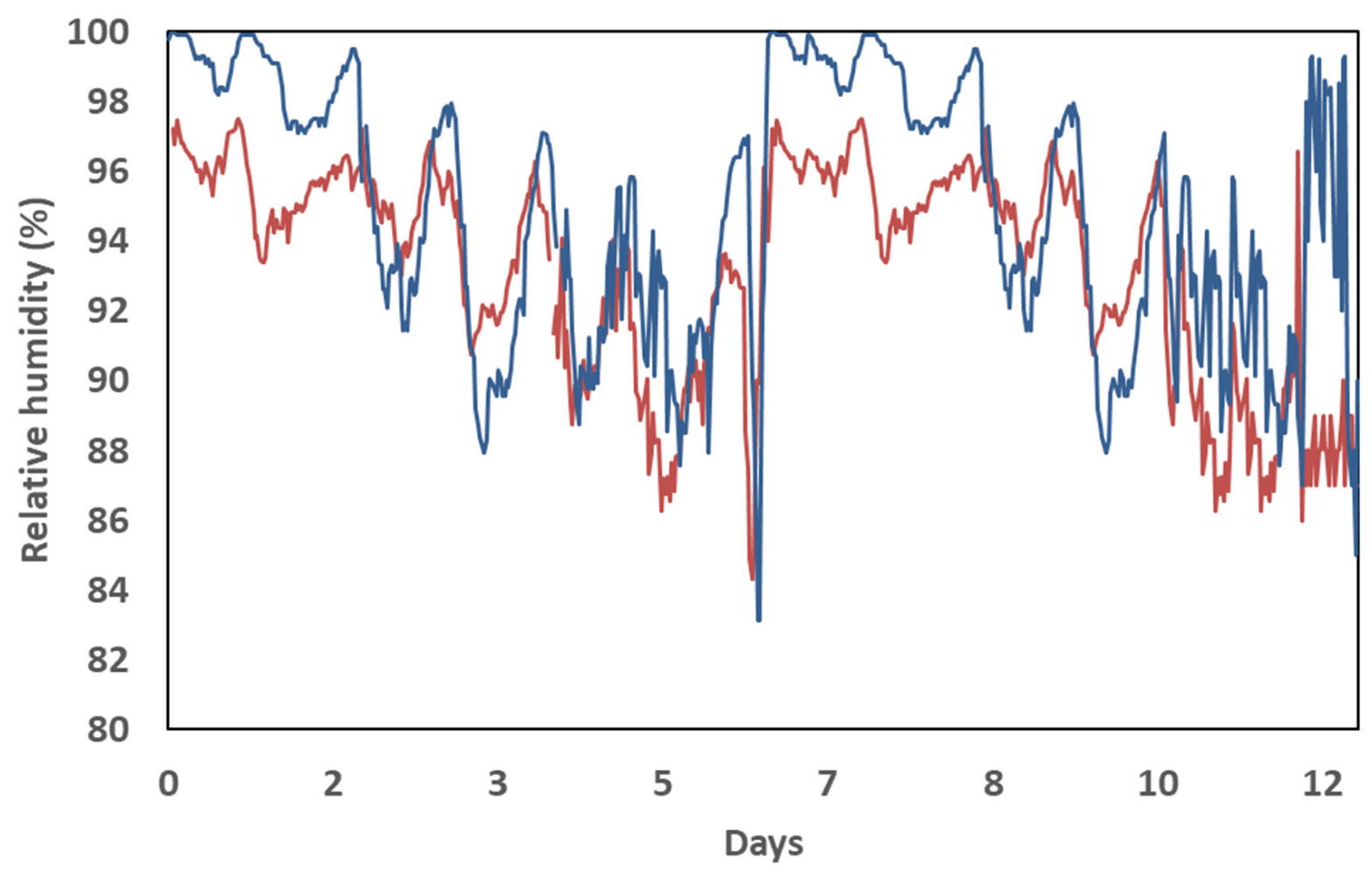

— Roots not wetted — Roots wetted

Figure 3. Relative humidity ( $\mathrm{RH} \%$ ) within the sacks of cassava roots during storage, either wetted by adding water or not wetted. On average, wetting increased the weight of roots by $0.7 \%$.

Considering the bag type, polypropylene bags resulted in the least PPD compared to the control, but this difference was only significant for the 12 day duration (Figure 4a). Considering the fungal rotting, the bags made from tarpaulin resulted in a significant improvement in shelf-life compared to the control, such that for just perceptible rots $(5 \%)$ the storage time was 8 days (Figure $4 \mathrm{~b}$ ). After eight days, the rotting was extensive in the roots, and the results for 10 and 12 days storage already exceeded the threshold rotting of $40 \%$ of roots and above. The other bag types (jute and tarpaulin) did not differ from the control. Regarding the roots' moisture content, bags made from tarpaulin resulted in the least reduction in moisture content during storage, followed by jute and lastly polypropylene $(p<0.05)$ (Figure $4 c)$. Most of the decline in moisture content was seen after 6 to 8 days. Regarding the starch content, storage in bags led to a lesser loss in starch content than in the control. Although there were significant differences between the bags with respect to starch content change, in practice the differences were small and hence the polypropylene bag was used for other experiments, as this is already used by the industry to transport cassava roots. In general, the decline in starch content started to occur after 2 days, but the loss did not accelerate until eight days of storage (Figure 4d); the starch loss after two days when stored in bags was about $0.3 \%$, and at eight days it was $2.4 \%$. If the roots were not stored in a bag, the starch loss was higher, at $4.3 \%$. 


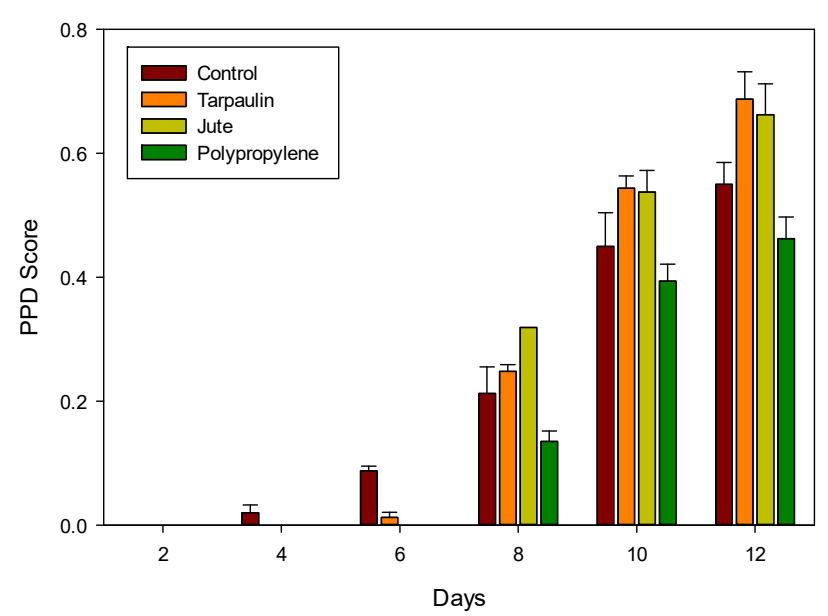

(a)

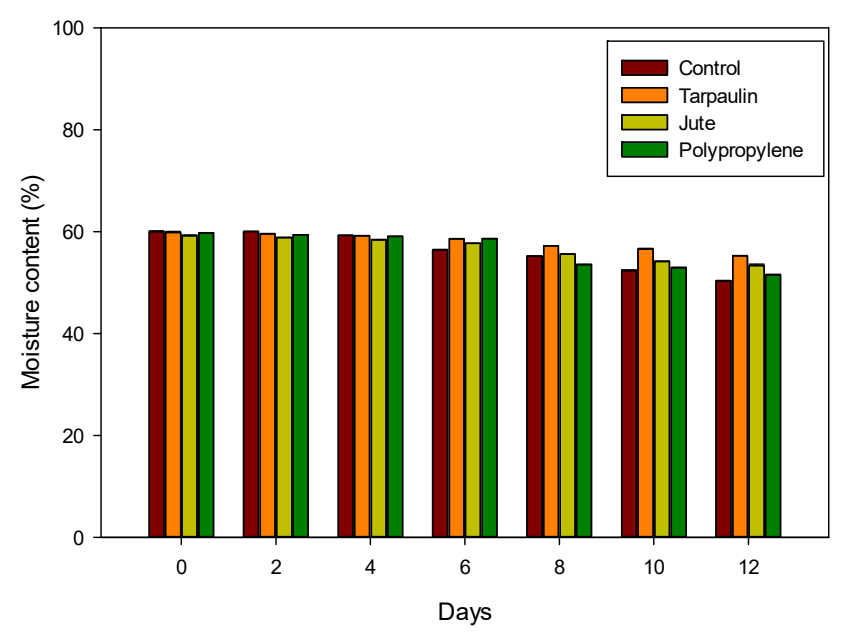

(c)

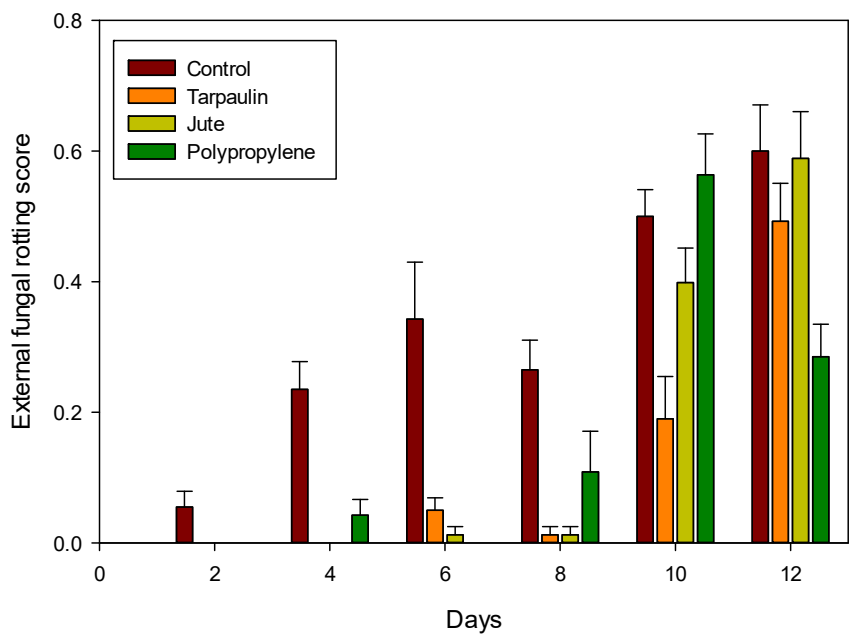

(b)

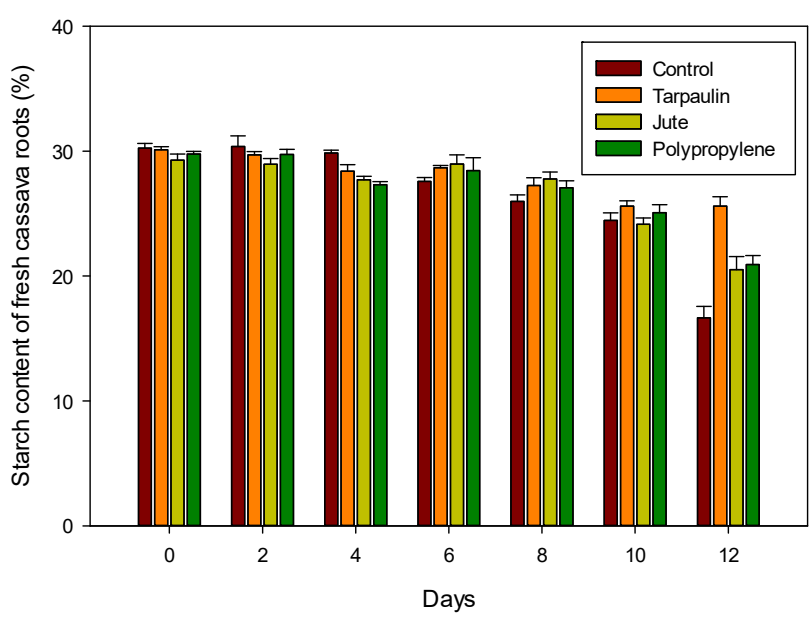

(d)

Figure 4. Variation in PPD (Postharvest physiological deterioration) score (a), fungal rot (b), moisture (c), and starch content (d) of fresh cassava roots with storage time in different types of bags.

\subsection{Effect of Root Damage on Shelf-Life}

Considering PPD measurements of the fresh cassava roots, after eight days (Figure 5) only roots with slight bruising or no bruising and no breaks had minimal discolouration. It should be noted that there was a slight increase in discolouration, but this was considered acceptable. However, roots that that were broken (either 1 or 2 breaks) or had extensive bruising resulted in significant discolouration. Regarding the extent of fungal rot, after eight days of storage roots with bruising (slight or extensive) and no breaks did not differ from the control sample (no breaks or bruising). However, the inclusion of extensive bruising was probably due to the wide variation between the replicates. However, any breaks (either 1 or 2 ) resulted in significant fungal rot. Considering the extent of starch loss after eight days of storage, where the roots were free of breaks or bruising (or had only slight bruising), the starch loss was $2.1 \%$ to $2.3 \%$. However, if the roots had any breaks or extensive bruising, the starch loss was higher, at $4.4 \%$ to $5.8 \%$ on average. 


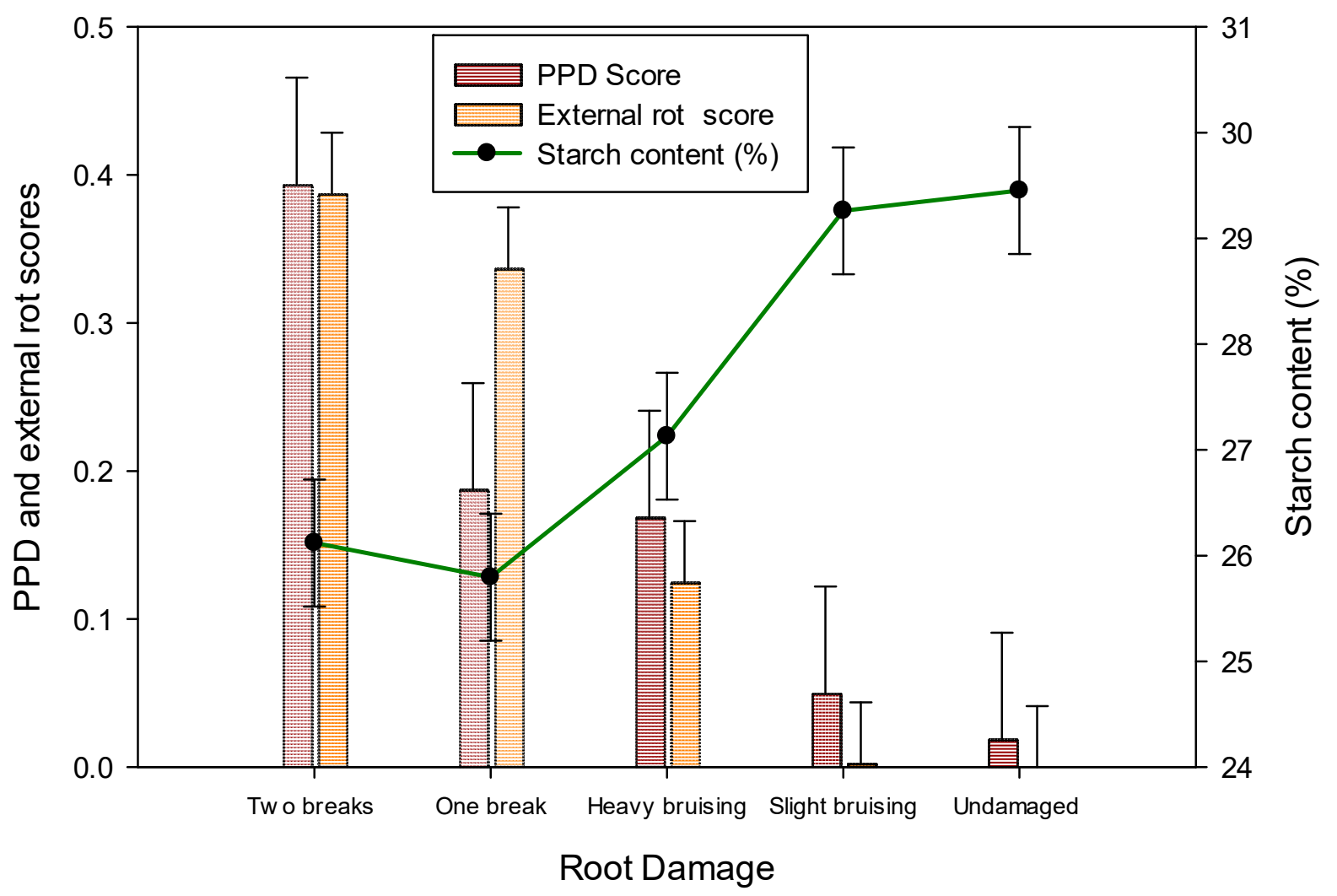

Figure 5. Changes in postharvest physiological deterioration (PPD), fungal rot, and starch content of fresh cassava roots with varying degrees of damage after 8 days of storage.

How the root is disconnected from the stem during harvesting might have an impact on storage. Processors of starch prefer to harvest without the peduncle because this part of the root is more fibrous, but keeping the peduncle attached is thought to increase the shelf-life (unpublished). Harvesting the roots with the peduncle did not have a significant impact on the starch content. It is speculated that there may have been no significant loss in starch content due to cutting without the peduncle because the additional damage to the fresh root was relatively minor, and as shown in the previous section, minor root damage did not adversely affect the shelf-life when storing for up to eight days.

\subsection{Effect of Cassava Variety}

The cassava variety (TME 419, TMS 0581 and TMS 1632) did not have a significant effect on root quality (PPD, fungal rot, starch content, or weight loss). Previously, weight loss occurring during storage was reported to be about $10 \%$ after two weeks of storage [1], but this is the first time that comparisons between these varieties have been reported. The starch content of the three varieties did change during storage, but the initial starch content of the different varieties were also different (Figure 6). Previously, during the storage of fresh roots, the starch loss was observed to occur at a rate of about $1 \%$ per day [1]. This research agrees with the loss in the starch of about $1 \%$ per day, but also shows that the curve is not linear, with little loss during the first $48 \mathrm{~h}$ and then increasing losses after this point. Zainuddin et al. [2] reported that starch losses might vary with variety; in this study, variety did not have an effect. A gap in this research was that possible differences might exist in starch gel clarity and swelling power and gel viscosity between varieties [1]. This would require further investigation. 


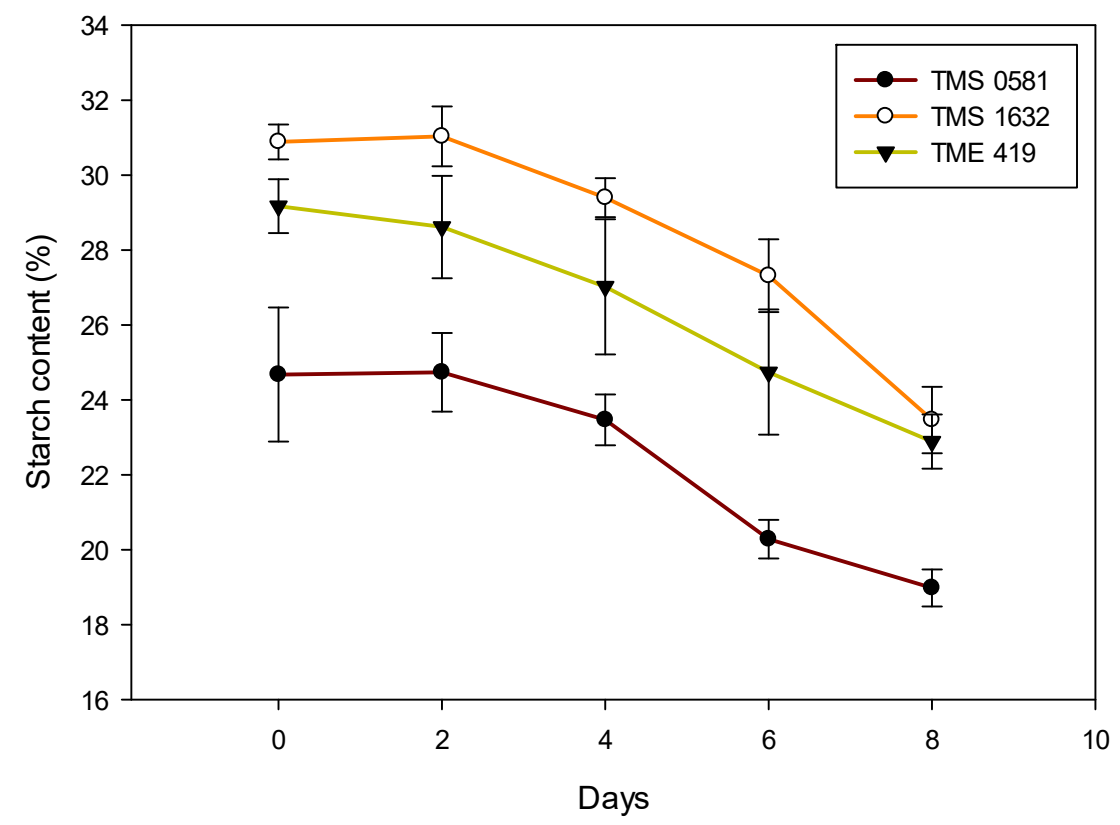

Figure 6. Variation in starch content of three varieties of cassava during storage of $50 \mathrm{~kg}$ in sacks.

\section{4. $\mathrm{CO}_{2}$ Concentration and Starch Losses}

Root damage is known to increase the rate of respiration in fresh cassava roots due to PPD and wound response along with a corresponding loss in starch [1,9]. This increase in respiration is associated with an increase in $\mathrm{CO}_{2}$ concentration, temperature, and $\mathrm{RH}$ $\%$ measured during storage, and could potentially be used to monitor changes in starch content during storage. While root damage did result in an increase in temperature and humidity in the stored fresh cassava roots, this did not significantly correlate with the extent of the starch loss. A significant correlation $(p<0.05)$ was found between starch loss $(\%)$ and maximum $\mathrm{CO}_{2}$ concentration measured at eight days (Figure 7). The maximum $\mathrm{CO}_{2}$ concentration was measured to account for the diurnal effect. While $\mathrm{CO}_{2}$ is known to be produced by the respiration of cassava roots, this is the first time that a relationship between $\mathrm{CO}_{2}$ concentration and starch loss in fresh cassava roots during storage has been reported. This research suggests that $\mathrm{CO}_{2}$ concentration in a cassava root store might be a suitable means to measure losses in starch, but would require further development.

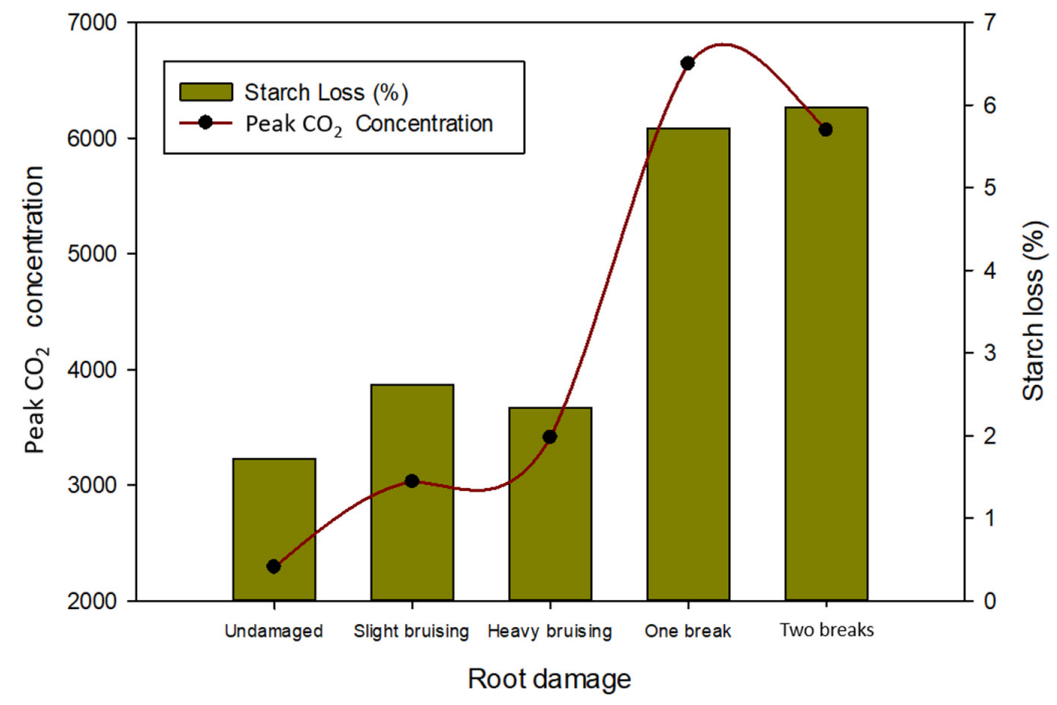

Figure 7. Relationship between starch loss (\%) and peak carbon dioxide concentration after eight days of storage. 


\section{Discussion}

Previously, more costly and logistically challenging chemical treatments (oxidising agents such as calcium hypochlorite, disinfectants such as ethanol, and fungicides such as benomyl, dicloran, and thiabendazole) have been used to increase the shelf-life of cassava roots by reducing PPD. Most of these chemicals probably only provide relief from secondary deterioration, which is microbial (mostly fungal rotting). Wax coatings $[17,18]$ have been reported to be successful in storing fresh cassava roots, which has been tested in Uganda. Edible surface coatings of fresh cassava roots are effective in preserving the quality of various perishable food products $[19,20]$. By using $1.5 \%$ xanthan guar/gum as an edible coating, cassava shelf life could be extended by up to 20 days at $25^{\circ} \mathrm{C}$. However, these approaches using chemical treatments were not included in this research because on a commercial scale, these methods would only be practical for high-value markets. Previous research has demonstrated that during the storage of fresh roots, starch loss occurs at a rate of about $1 \%$ per day [6] and might vary by variety and storage conditions [21,22]. Reported changes in the starch qualities during storage include a reduction in gel clarity and swelling power and an increase in gel viscosity; it is not known how these changes reflect the quality of the starch or its commercial value $[4,23]$. In this research, the effect of gel clarity and swelling power was not measured, and this would require further research.

The temperature, $\mathrm{RH} \%$, and $\mathrm{CO}_{2}$ in the sacks were similar regardless of the bag material, and this supports the findings that the bag material and addition of water had little effect. The average temperature varied between 27.1 and $29.1{ }^{\circ} \mathrm{C}$ and was within the range of 25 to $35{ }^{\circ} \mathrm{C}$ recommended by [12,24], while the average relative humidity varied between $92 \%$ and $98 \%$, which is above the value of $85 \%$ for curing $[25,26]$. However, as the ambient conditions for humidity were also high at $74 \%$, the higher humidities were probably acceptable. Previously, different bag materials have been compared for storing fresh cassava roots, such as open weave (manmade fibres), polyethylene $(0.13 \mathrm{~mm}$ thick), and recycled rice/flour sacks made of tightly woven polyethylene. Of these, the polyethylene and recycled rice sacks were reported to retard deterioration the most [13]. In this research, $50 \mathrm{~kg}$ of cassava roots could be kept for up to eight days, irrespective of whether the roots were wet or dry and irrespective of the bag material. The loss in starch content, a key commercial product requirement, was reduced if the fresh roots were stored in bags, and was about $2.4 \%$ on average over eight days. This is less than the $8 \%$ over eight days (i.e., $1 \%$ per day of storage) reported by Sánchez et al. [6]. The difference in starch losses might be because we stored only a few roots and each was stored individually rather than in bags.

Root damage had an impact on the quality of the roots with respect to PPD, fungal rot, and starch content. Previous research has demonstrated that physical damage to the fresh roots (cuts, breaks, and bruising) increased PPD and reduced shelf-life [1,2,4,27]. After 11 days of storage, roots with slight damage lost $9.6 \%$ in weight compared to $18.2 \%$ for roots with severe damage [6]. In response to wounding, such as cuts and abrasions, cassava storage roots show early physiological changes, including increased respiratory rate and water loss. Increased respiration induces the conversion of starch to sugar $[6,28]$. During storage, the starch content of unwounded cassava storage roots gradually decreases. However, starch loss and sugar production during storage are significantly higher if the roots are wounded. This research is new in that the type of root damage (bruising or breaks) was considered. As the fresh cassava root remains biologically active, PPD is accompanied by an increase in respiration and the root can initiate a wound response, and discolouration of the roots (vascular streaking) occurs due to oxidation of secondary metabolites [1]. However, previous research was undertaken on only a few cassava roots and hence, little was known about the response with larger sample sizes or how much root damage was possible before PPD became unacceptable. This research, using larger sample sizes of $50 \mathrm{~kg}$, shows that while root damage does reduce the shelf-life, slight bruising of the root is acceptable provided the roots are not cut or broken. 


\section{Conclusions}

Currently, for the processing of cassava roots in the production of high-quality cassava flour or starch, a limitation is the rapid deterioration of the roots within $48 \mathrm{~h}$ after harvesting. It can be concluded that fresh cassava roots $(50 \mathrm{~kg})$ can be stored in a bag at ambient temperature in West Africa for up to eight days with minimal deterioration or loss in starch. The advantage would be reduced product handling and potentially lower costs when transporting the fresh cassava roots from the farm to the processing factory.

Several control measures would be required to support the management of the process to ensure that roots can be consistently stored. This includes minimizing root damage. Our results suggest that there is no need to wet the roots, harvest with the peduncle attached, or separate different varieties (TME 419, TMS 0581 and TMS 1632). Other varieties may have different storage characteristics, and this would need to be tested.

A new approach to monitoring starch losses in fresh cassava roots during storage using a simple carbon dioxide sensory is suggested, but would require further testing. In industrial applications, this could provide a potential way to continuously and remotely monitor large quantities of cassava roots, avoid postharvest losses, and maintain profitability.

Author Contributions: K.T., C.I.O., L.O.S., A.P., and B.B. conceived and planned the experiments. C.I.O., A.F.A., and A.-R.A.A. carried out the experiments. K.T. and A.P. took the lead in writing the manuscript. All authors provided critical feedback and helped shape the research, analysis, and manuscript. All authors have read and agreed to the published version of the manuscript.

Funding: This research was funded by Rockefeller Foundation, Cassava Challenge Fund 2018.

Institutional Review Board Statement: Not Applicable.

Informed Consent Statement: Not applicable.

Acknowledgments: The authors would like to thank the Rockefeller Foundation for providing the financial support for these experiments. These laboratory studies would not have been possible without the support of numerous people in Nigeria. We particularly want to mention the staff of Federal University of Agriculture, Abeokuta (FUNAAB). Notwithstanding, the content of this report represents the views of the authors only.

Conflicts of Interest: The authors declare no conflict of interest.

\section{References}

1. Reilly, K.; Gómez-Vásquez, R.; Buschmann, H.; Tohme, J.; Beeching, J.R. Oxidative stress responses during cassava post-harvest physiological deterioration. Plant Mol. Biol. 2004, 56, 621-637. [CrossRef] [PubMed]

2. Zainuddin, I.M.; Fathoni, A.; Sudarmonowati, E.; Beeching, J.R.; Gruissem, W.; Vanderschuren, H. Cassava post-harvest physiological deterioration: From triggers to symptoms. Postharvest Biol. Technol. 2017, 142, 115-123. [CrossRef]

3. Parmar, A.; Sturm, B.; Hensel, O. Crops that feed the world: Production and improvement of cassava for food, feed, and industrial uses. Food Secur. 2017, 9, 5. [CrossRef]

4. Blagbrough, I.S.; Bayoumi, S.A.L.; Rowan, M.G.; Beeching, J.R. Cassava: An appraisal of its phytochemistry and its biotechnological prospects. Phytochemistry 2010, 71, 1940-1951. [CrossRef]

5. Bayoumi, S.A.L.; Rowan, M.G.; Beeching, J.R.; Blagbrough, I.S. Constituents and secondary metabolite natural products in fresh and deteriorated cassava roots. Phytochemistry 2010, 71, 598-604. [CrossRef]

6. Sánchez, T.; Dufour, D.; Moreno, J.L.; Pizarro, M.; Aragón, I.J.; Domínguez, M.; Ceballos, H. Changes in extended shelf life of cassava roots during storage in ambient conditions. Postharvest Biol. Technol. 2013. [CrossRef]

7. Mahmod, N.; Beeching, J. Correlation of scopoletin-induced fluorescence with visible PPD symptoms in greenhouse cassava. Postharvest Biol. Technol. 2018, 145, 10-14. [CrossRef]

8. Carter, S.E.; Fresco, L.O.; Jones, P.G.; Fairbairn, J.N. Introduction and Diffusion of Cassava in Africa. IITA (International Institute of Tropical Agriculture), Ibadan, Nigeria. 1995. Available online: https:/ /www.researchgate.net/publication/40207427 _Introduction_and_diffusion_of_cassava_in_Africa (accessed on 20 February 2020).

9. Parmar, A.; Fikre, A.; Sturm, B.; Hensel, O. Post-harvest management and associated food losses and by-products of cassava in southern Ethiopia. Food Secur. 2018, 10, 419-435. [CrossRef]

10. Osunde, Z.D.; Fadeyibi, A. Storage Methods and Some Uses of Cassava in Nigeria. Cont. J. Agric. Sci. $2012,5,12-18$.

11. Reynolds, T.W.; Waddington, S.R.; Anderson, C.L.; Chew, A.; True, Z.; Cullen, A. Environmental impacts and constraints associated with the production of major food crops in Sub-Saharan Africa and South Asia. Food Secur. 2015, 7, 795-822. [CrossRef] 
12. Booth, R.H. Storage of fresh cassava (Manihot esculenta). I. Post-harvest deterioration and its control. Exp. Agric. 1976, 12, 103-111. [CrossRef]

13. Bancroft, R.D.; Crentsil, R.D. Application of a Low-Cost Storage Technique for Fresh Cassava (Manihot esculenta) Roots in Ghana. In Transformation Alimentaire du Manioc; AgborEgbe, T., Brauman, A., Griffon, D., Treche, S., Eds.; ORSTOM Ed.: Paris, France, 1995; pp. 547-555.

14. Rees, D.; van Oirschot, Q.E.A.; Aked, J. The role of carbohydrates in wound-healing of sweetpotato roots at low humidity. Postharvest Biol. Technol. 2008, 50, 79-86. [CrossRef]

15. Atieno, L.; Owino, W.; Ateka, E.M.; Ambuko, J. Effect of surface coatings on the shelf life and quality of cassava. J. Food Res. 2018, 7, 46-60.

16. Zidenga, T. Delaying Post-Harvest Physiological Deterioration in Cassava. Virginia Tech Blacksburg, VA. 2012. Available online: http:/ / www.isb.vt.edu/news/2012/Aug/Zidenga.pdf (accessed on 20 February 2020).

17. Uchechukwu-Agua, A.D.; Caleb, O.J.; Opara, U.L. Postharvest Handling and Storage of Fresh Cassava Root and Products: A Review. Food Bioprocess Technol. 2015, 8, 729-748. [CrossRef]

18. Naziri, D.; Quaye, W.; Siwoku, B.; Wanlapatit, S.; Phu, T.V.; Bennett, B. The diversity of postharvest losses in cassava value chains in selected developing countries. J. Agric. Rural Dev. Trop. Subtrop. 2014, 115, 111-123.

19. El-Mogy, M.M.; Parmar, A.; Ali, M.R.; Abdel-Aziz, M.E.; Abdeldaym, E.A. Improving postharvest storage of fresh artichoke bottoms by an edible coating of Cordia myxa gum. Postharvest Biol. Technol. 2020, 163, 111143. [CrossRef]

20. Haq, M.A.; Azam, M.; Hasnain, A. Gum cordia as carrier of antioxidants: Effects on lipid oxidation of peanuts. J. Food Sci. Technol. 2015, 52, 2366-2372. [CrossRef] [PubMed]

21. Campo, B.V.H.; Hyman, G.; Bellotti, A. Threats to cassava production: Known and potential geographic distribution of four key biotic constraints. Food Secur. 2011, 3, 329-345. [CrossRef]

22. Rees, D.; Wesby, A.; Tomlins, K.; van Oirschot, Q.; Cheema, U.; Cornelius, E.W.; Amjad, M. Tropical Root Crops. In Crop Post-Harvest: Science and Technology: Perishables, 1st ed.; Rees, D., Farrel, G., Orchard, J., Eds.; Wiley Blackwell Publishing Ltd.: Sussex, UK, 2012; pp. 392-396.

23. Brimer, L. Chapter 10-Cassava Production and Processing and Impact on Biological Compounds. In Processing and Impact on Active Components in Food; Preedy, V., Ed.; Academic Press: San Diego, CA, USA, 2015; pp. 81-87.

24. Noon, R.A.; Booth, R.H. Nature of post-harvest deterioration of cassava roots. Trans. Br. Mycol. Soc. 1977, 69, 287-290. [CrossRef]

25. Ray, R.C.; Ravi, V. Post harvest spoilage of sweetpotato in tropics and control measures. Crit. Rev. Food Sci. Nutr. 2005, 45, 623-644. [CrossRef]

26. Kader, A.A. Postharvest Technology of Horticultural Crops-An Overview from Farm to Fork. J. Appl. Sci. Technol. 2013, 1, 1-8.

27. Uarrota, V.G.; Moresco, R.; Coelho, B.; da Costa Nunes, E.; Peruch, L.A.M.; de Oliverra Neubert, E.; Rocha, M.; Maraschin, M. Metabolomics combined with chemometric tools (PCA, HCA, PLS-DA and SVM) for screening cassava (Manihot esculenta Crantz) roots during postharvest physiological deterioration. Food Chem. 2014, 161, 67-78. [CrossRef] [PubMed]

28. El-Sharkawy, M.A. Physiological characteristics of cassava tolerance to prolonged drought in the tropics: Implications for breeding cultivars adapted to seasonally dry and semiarid environments. Braz. J. Plant Physiol. 2007, 19, 257-286. [CrossRef] 